\title{
Outcomes in elderly patients treated with a single-agent or combination regimen as first-line chemotherapy for recurrent or metastatic gastric cancer
}

\author{
Der Sheng Sun • Eun Kyoung Jeon • Hye Sung Won • \\ Ji Chan Park • Byoung Young Shim · Suk Young Park • \\ Young Seon Hong $\cdot$ Hoon Kyo Kim $\cdot$ Yoon Ho Ko
}

Received: 24 March 2014/ Accepted: 13 July 2014/Published online: 7 August 2014

(C) The International Gastric Cancer Association and The Japanese Gastric Cancer Association 2014

\begin{abstract}
Background Palliative chemotherapy is used to prolong survival among elderly patients with inoperable gastric cancer (GC). We analyzed differences between single and combination first-line palliative chemotherapy among these patients.

Methods Included patients were $>70$ years old and were treated for GC at four clinical centers of the Catholic University of Korea. Baseline characteristics, the first-line chemotherapy regimen, treatment responses, toxicities, progression-free survival (PFS), and overall survival (OS) were evaluated.

Results Between 2005 and 2012, $178>70$-year-old patients with GC received palliative chemotherapy using
\end{abstract}

D. S. Sun · H. S. Won · Y. H. Ko (ه)

Division of Oncology, Department of Internal Medicine, Uijeongbu St. Mary's Hospital, College of Medicine, The Catholic University of Korea, 222 Banpo-daero, Seocho-gu, Seoul 137-701, Republic of Korea

e-mail: koyoonho@catholic.ac.kr

E. K. Jeon · Y. S. Hong

Division of Oncology, Department of Internal Medicine, Seoul

St. Mary's Hospital, College of Medicine, The Catholic

University of Korea, 222 Banpo-daero, Seocho-gu,

Seoul 137-701, Republic of Korea

J. C. Park · S. Y. Park

Division of Oncology, Department of Internal Medicine,

Daejeon St. Mary's Hospital, College of Medicine, The Catholic

University of Korea, 222 Banpo-daero, Seocho-gu,

Soeul 137-701, Republic of Korea

\section{B. Y. Shim · H. K. Kim}

Division of Oncology, Department of Internal Medicine,

St. Vincent's Hospital, College of Medicine, The Catholic

University of Korea, 222 Banpo-daero, Seocho-gu,

Seoul 137-701, Republic of Korea single or combination regimens. Median ages were 77 years (range 71-89) in the single regimen group (SG, 70 patients) and 73 years (range 71-81) in the combination group (CG, 108 patients). Patients in the SG received S- 1 or capecitabine. The most common regimen in the CG was platinum combined with fluorouracil. The most common response in both groups was stable disease (SG, $45.7 \%$; CG, $48.1 \%$ ). In the SG and CG, median PFS times were 4.4 months (95\% confidence interval $[\mathrm{CI}] 2.85-5.95)$ and 4.1 months (95\% CI 2.62-5.57; $P=0.295$ ), respectively; median OS times were 6.6 months (95\% CI 4.17-9.08) and 7.6 months (95\% CI 5.50-9.69; $P=0.782)$, respectively. Hematologic $(P<0.001)$ and non-hematologic toxicities $(P<0.001)$ were more frequent in the $\mathrm{CG}$. The most common causes of chemotherapy cessation were disease progression in the SG and decreased performance status in the CG.

Conclusions Single-agent treatment should be considered a first-line palliative chemotherapy option for elderly patients with GC.

Keywords First-line chemotherapy - Gastric cancer . Old age $\cdot$ Palliative chemotherapy $\cdot$ Metastasis .

Cancer recurrence

\section{Introduction}

At diagnosis, nearly half of patients with gastric cancer (GC) have inoperable stage disease [1]. Local and distant recurrences are also frequent in cases of resected GC. Chemotherapy plays an important role in improving survival and quality of life in this population [2, 3]. In early studies of chemotherapy compared with best supportive care, a significant prolongation of survival was observed in the groups receiving chemotherapy [2, 3]. In phase II and 
III trials, continuous fluorouracil (5-FU) combined with cisplatin (FP) showed a response rate (RR) of $40 \%$ with a median survival duration of 7 to 10.6 months [4-6]. Accordingly, FP has been widely accepted as a first-line chemotherapy for GC. As compared with FP, the capecitabine/cisplatin combination regimen has been shown to be non-inferior in terms of progression-free survival (PFS) (5.6 vs. 5.0 months) and overall survival (OS) (10.5 vs. 9.3 months) [7]. In the SPIRITS trial, which compared a $\mathrm{S}-1 /$ cisplatin combination with $\mathrm{S}-1$ alone in chemotherapynaïve patients with advanced $\mathrm{GC}$, the combination regimen showed a higher RR (54 vs. $31 \%$ ) and improved median survival (13 vs. 11 months) [8]. In the REAL-2 study, capecitabine and oxaliplatin was demonstrated to be another standard treatment option [9]. However, most patients older than 70 years were excluded from these clinical trials and, accordingly, the impact of chemotherapy has not been evaluated for these patients [10].

Among persons older than 65 years, gastric cancer is one of the most common cancers and one of the leading causes of death in Korean patients with cancer [11]. Advanced GC currently causes 36,000 deaths per year in Korea, at a median age of 75 years [11]. The incidence of GC in elderly individuals is still increasing, with a peak incidence occurring in the seventh decade [12, 13]. According to recent results from the Surveillance, Epidemiology, and End Results cancer registry in the United States, $65.5 \%$ of GCs are diagnosed in patients older than 65 years, the median age at GC diagnosis is 71 years, and the median age of GC-related death is 74 years [14]. In the process of aging, natural changes in physiologic and functional status, drug pharmacokinetics, and organ function cannot be avoided. The elderly are frequently affected by declines in marrow reserve, lean body mass, drug clearance, and general health status; concomitant comorbidities; and pronounced tumor symptoms [15, 16]. However, age itself is not a negative predictive factor, and treatment should not be omitted on the basis of chronological age alone [17]. In a randomized phase II trial comparing the single oral agents capecitabine and S-1 in patients older than 65 years, the RRs were 26 and $29 \%$, the median PFS times were 4.7 months and 4.2 months, the median OS times were 9.5 months and 8.2 months, and grade 3 severe adverse events occurred in less than $10 \%$ of patients [18]. Although it is widely accepted that active treatment for advanced GC in the elderly is important, the treatment of elderly patients (over 70 years old) with incurable advanced GC is not guided by current evidence regarding the tolerability of regimens and agents (single or combination) in the elderly.

In this study, we sought to analyze chemotherapy regimens in patients with GC who were older than 70 years, specifically comparing the efficacy and safety of single and combination agents for first-line treatment. We also investigated the prognostic relevance of clinical data, such as performance status (PS), comorbidity, and TNM stage, among elderly patients with GC.

\section{Patients and methods}

\section{Patient eligibility}

We evaluated patients with recurrent or metastatic GC at four participating centers in South Korea between January 2005 and June 2012. The criteria for study inclusion were as follows: (1) age above 70 years, (2) cytologically or histologically proven recurrent or metastatic gastric cancer, (3) receipt of palliative chemotherapy, (4) no prior palliative chemotherapy or radiotherapy before receiving first-line palliative chemotherapy, and (5) adequate physiological organ function. Medical records were collected, including data on patient characteristics, operations, pathology reports, chemotherapy regimens, responses, toxicity profiles, date of progression, date of last follow up, and death. Comorbidity was classified according to the Charlson comorbidity index (CCI), which provides a weighted index of comorbidity, according to the relative risks of death associated with 19 clinical conditions. PS was evaluated according to the Eastern Cooperative Oncology Group (ECOG) criteria. This study was approved by the institutional review board of a center approved by the Association for the Accreditation of Human Research Protection Program. The study was performed in full accordance with the precepts of the Declaration of Helsinki.

\section{Efficacy and toxicity of the treatment}

Chemotherapy was discontinued if disease progression was noted, irreversible grade 3 or 4 toxicity was noted, or if the patient wished to discontinue the treatment. Chemotherapy was postponed until recovery of bone marrow function was attained. The investigators decided to stop consecutive chemotherapy if the patient experienced an objective decline in PS. Tumors were measured every 2 months at each center until onset of progressive disease, and the patients were evaluated using computed tomography to determine anti-tumor efficacy, following RECIST 1.1. Complete response (CR) was defined as the disappearance of all tumor lesions. Partial response (PR) was defined as an estimated $\geq 30 \%$ decrease in tumor size with no detectable new lesions. Progressive disease (PD) was defined as the appearance of any new tumor lesions or a $\geq 20 \%$ increase in the size of the existing tumor lesions. When responses did not qualify as CR, PR, or PD, they were reported as stable disease (SD). Toxicity was assessed 
on day 1 of every cycle. Toxicity was graded according to NCI CTC version 3.0.

\section{Statistical analysis}

The following treatment outcomes were evaluated: RR, disease control rate (DCR), PFS, and OS. The efficacy analysis followed an intention-to-treat approach. PFS was defined as the interval between the date of the diagnosis of recurrence or metastatic disease and the date of disease progression or death from any cause. OS was defined as the interval between the date of the diagnosis of recurrence or metastatic disease and the date of death from any cause. The Kaplan-Meier method was employed to estimate the probability of survival, and survival differences were analyzed using the log-rank test. The two-sided significance level was set at $P<0.05$. Factors included the univariate analyses (using Kaplan-Meier methods) were gender, age, recurrence, history of operations, CCI, pathology grade, treatment, ECOG PS, T stage, N stage, and the number of metastasized regions. Each factor with a $P<0.2$ association in the univariate analysis was selected and included in the multivariate analysis. The multivariate analysis was performed using the Cox proportional hazards regression model, which provided adjusted hazard ratios (HR) that were used to determine prognostic factors for OS. $P<0.05$ was considered significant for all analysis. The Chi square test and Fisher's exact test were used to compare the distributions of clinical parameters between different groups.

\section{Results}

Patients' characteristics

From January 2005 to June 2012, 705 patients were screened at the four medical centers. Patients who received best supportive care, transferred to other hospitals, or were lost to follow up were excluded. In total, 178 patients fulfilled the inclusion criteria and were enrolled in this retrospective analysis. Seventy patients received a singleagent regimen and, accordingly, were assigned to the single regimen group (SG). The remaining 108 patients received a combination regimen and were assigned to the combination regimen group (CG). The clinical characteristics of these patients are presented in Table 1 . The median age in the SG was 77 years (range 71-89), and the median age in the CG was 73 years (range 71-81). The CG included a significantly greater proportion of patients aged 71-79 years $(P=0.001)$. In the SG and CG, 45.7 and $61.2 \%$ of patients had an ECOG PS of 0 or $1(P=0.037)$. In both groups, more than half of the patients had lower (0-2)
Table 1 Clinical characteristics of the patients

\begin{tabular}{|c|c|c|c|}
\hline & $\begin{array}{l}\text { Single } \\
\text { group, } n(\%)\end{array}$ & $\begin{array}{l}\text { Combination } \\
\text { group, } n(\%)\end{array}$ & $P$ value \\
\hline Patients $(n)$ & 70 & 108 & \\
\hline $\begin{array}{l}\text { Age (years), median } \\
\text { (range) }\end{array}$ & $77(71-89)$ & $73(71-81)$ & 0.001 \\
\hline $71-79$ & $52(74.3)$ & $106(98.1)$ & \\
\hline$\geq 80$ & $18(25.7)$ & $2(1.9)$ & \\
\hline Gender & & & 0.070 \\
\hline Female & $24(34.3)$ & $24(22.2)$ & \\
\hline Male & $46(64.7)$ & $84(77.8)$ & \\
\hline Pathology & & & 0.370 \\
\hline TAC & $61(87.1)$ & 97 (90.6) & \\
\hline Others & $9(12.9)^{\mathrm{a}}$ & $11(10.2)^{b}$ & \\
\hline Tumor grade & & & 0.630 \\
\hline Well & $6(8.6)$ & $10(9.2)$ & \\
\hline Moderately & $25(35.7)$ & $38(35.2)$ & \\
\hline Poorly & $30(42.9)$ & $57(52.8)$ & \\
\hline Unknown & $1(12.8)$ & $3(2.8)$ & \\
\hline Measurable lesion & & & 0.870 \\
\hline Yes & $63(90.0)$ & $98(90.7)$ & \\
\hline No & $7(10.0)$ & $10(9.3)$ & \\
\hline ECOG PS & & & 0.037 \\
\hline $0-1$ & $32(45.7)$ & $66(61.2)$ & \\
\hline $2-3$ & $38(54.3)$ & $42(38.8)$ & \\
\hline $\begin{array}{l}\text { Charlson comorbidity } \\
\text { index }\end{array}$ & & & 0.351 \\
\hline $0-2$ & $61(87.2)$ & $92(85.2)$ & \\
\hline $3-4$ & $9(12.8)$ & $16(14.8)$ & \\
\hline $\mathrm{T}$ stage & & & 0.227 \\
\hline $1-2$ & $5(7.1)$ & $17(15.7)$ & \\
\hline $3-4$ & $58(82.9)$ & $80(74.1)$ & \\
\hline Unknown & $7(10.0)$ & $11(10.9)$ & \\
\hline $\mathrm{N}$ stage & & & 0.276 \\
\hline 0 & $2(2.9)$ & $4(3.7)$ & \\
\hline $1-3$ & $63(90)$ & $88(81.5)$ & \\
\hline Unknown & $5(7.1)$ & $16(14.8)$ & \\
\hline M stage & & & 0.869 \\
\hline 0 & $16(22.9)$ & $29(26.9)$ & \\
\hline 1 & $50(71.4)$ & $70(64.8)$ & \\
\hline Unknown & $4(5.7)$ & $9(8.3)$ & \\
\hline TNM Stage & & & 0.455 \\
\hline III & $12(17.0)$ & $18(16.6)$ & \\
\hline IV & $52(74.2)$ & $79(73.1)$ & \\
\hline $\begin{array}{l}\text { Estimated } \mathrm{Cr} \mathrm{Cl} \text { rate }(\mathrm{ml} / \\
\min )^{\mathrm{c}} \text {, median (range) }\end{array}$ & $\begin{array}{l}52.6 \\
\quad(25.4-74.8)\end{array}$ & $\begin{array}{l}54.4 \\
\quad(24.6-79.1)\end{array}$ & 0.870 \\
\hline$<30$ & $21(30.0)$ & $35(32.4)$ & \\
\hline$\geq 30,<50$ & $31(44.3)$ & $55(51.0)$ & \\
\hline$\geq 50$ & $18(25.7)$ & 18 (16.6) & \\
\hline BSA, median (range) & & & 0.217 \\
\hline$<1.25$ & $5(7.1)$ & $1(0.9)$ & \\
\hline
\end{tabular}


Table 1 continued

\begin{tabular}{llll}
\hline & $\begin{array}{l}\text { Single } \\
\text { group, } n(\%)\end{array}$ & $\begin{array}{l}\text { Combination } \\
\text { group, } n(\%)\end{array}$ & $P$ value \\
\hline$\geq 1.25,<1.5$ & $26(37.1)$ & $42(38.9)$ & \\
$\geq 1.5$ & $39(55.7)$ & $65(60.2)$ & \\
$\begin{array}{l}\text { Number of distant } \\
\text { metastasis }\end{array}$ & & & 0.675 \\
1 & $32(45.7)$ & $47(43.5)$ & \\
2 & $27(38.6)$ & $38(35.2)$ & \\
$\geq 3$ & $5(7.1)$ & $14(13.0)$ & \\
Recurrent cases & $7(10.0)$ & $27(25.0)$ & 0.013 \\
Previous surgery & & & 0.014 \\
$\quad$ Yes & $19(27.1)$ & $49(45.4)$ & \\
No & $51(54.6)$ & $59(54.6)$ & \\
\hline
\end{tabular}

TAC tubular adenocarcinoma, EGOG PS Eastern Cooperative Oncology Group Performance Status, BSA Body Surface Area

${ }^{a}$ Signet-ring cell carcinoma

b Signet-ring cell carcinoma (9 patients, $8.4 \%$ ), undifferentiated carcinoma (1 patient, $1.0 \%$ )

${ }^{\mathrm{c}}$ Estimated creatinine clearance rate using Cockcroft-Gault formula

CCIs. Recurrent GC was more frequent and the proportion of patients who underwent operations before recurrence was higher in the CG. Other parameters related to patient characteristics did not significantly differ between the two groups.

\section{Chemotherapy}

As first-line chemotherapy, 70 patients received singleagent chemotherapy and 108 patients were treated with combination agents. Standard doses and schedules for each regimen are listed in Table 2. In the SG, S-1 was administered to 45 patients $(64.3 \%)$ and capecitabine was administered to 25 patients $(35.7 \%)$. Of the combination chemotherapy regimens, fluorouracil plus platinum regimens (fluorouracil plus cisplatin, S-1 plus cisplatin, capecitabine plus cisplatin, or leucovorin plus fluorouracil plus oxaliplatin [FOLFOX]) were administered to 97 patients $(90.0 \%)$, taxane plus platinum regimens (paclitaxel plus cisplatin or docetaxel plus cisplatin) were administered to seven patients $(6.5 \%)$, leucovorin plus fluorouracil plus irinotecan (FOLFIRI) was administered to two patients $(1.9 \%)$, and fluorouracil plus docetaxel was administered to two patients (1.9\%). Patients in the SG and CG received medians of three (range 1-12) and five (range 1-14) chemotherapy cycles, respectively, constituting a significantly greater number of treatment cycles in the $\mathrm{CG}$ group $(P=0.001)$. However, the median duration of treatment did not differ significantly between the SG (4.9 months, range 1.2-18.5) and the CG (5.8 months, range 0.3-27.2) $(P=0.261)$.
The median relative dose intensities were $92.4 \%$ (range $50-100)$ in the SG, and $83.5 \%$ (range 43-100) in the CG $(P<0.001)$. Although the objective RR was higher in the CG than in the SG (24.0 vs. $8.6 \%, P=0.015)$, DCR did not differ significantly between the CG and the SG (72.1 vs. $54.3 \%, P=0.157$; Table 3 ). The most common causes of chemotherapy cessation were disease progression in the SG and decreased performance status in the CG (Table 4). After disease progression, 20 patients $(28.6 \%)$ in the SG and 44 patients $(40.7 \%)$ in the CG were treated with second-line chemotherapy.

Survival and prognostic factors

The median durations of follow-up were 9.3 months (range 0.9-53.7) in the SG and 9.6 months (range 0.5-39.8) in the CG. Analysis of the survival data revealed 62 death events in the SG and 97 death events in the CG. Median PFS times were 4.4 months (95\% confidence interval [CI] 2.85-5.95) in the SG and 4.1 months (95\% CI 2.62-5.57) in the CG, $(P=0.295)$ (Fig. 1a). Median OS times were 6.6 months (95\% CI 4.17-9.08) in the SG and 7.6 months $(95 \% \mathrm{CI}$ 5.50-9.69 in the CG $(P=0.782)$ (Fig. 1b). Neither PFS nor OS significantly differed between the two groups. The univariate analyses demonstrated that three clinical factors were significantly associated with a shorter OS: $\mathrm{T}$ stage, $\mathrm{N}$ stage, and the number of metastasized regions (data not shown). In the multivariate Cox proportional hazards regression analysis (Table 5), $\mathrm{N}$ stage (recurrence-adjusted HR 3.620, $95 \%$ CI $1.303-10.062 ; P=0.014$ ) was prognostic factor that was significantly and independently associated with OS. The type of chemotherapy (single agent or combination) was not significantly associated with $\mathrm{OS}$ in the multivariate regression (recurrence-adjusted HR $1.010,95 \%$ CI $0.658-1.552, P=0.963)$.

\section{Toxicities}

In the SG, NCI-CTC grade 3 or 4 hematological toxicities comprised leukopenia in two patients $(6.2 \%)$ and anemia in one patient $(4.0 \%)$. In the CG, grade 3 or 4 hematological toxicities comprised neutropenia in 27 patients $(25.0 \%)$, leukopenia in 20 patients $(18.5 \%)$, and anemia in five patients $(4.6 \%)$. In the CG, grade 3 or 4 nonhematological toxicities included asthenia $(13.0 \%)$, nausea/vomiting $(6.5 \%)$, peripheral neuropathy $(25.0 \%)$, mucositis $(2.8 \%)$, and infection $(1.9 \%)$. There were no treatment-related deaths. With respect to the major chemotherapeutic regimens, globally, the adverse events in fluorouracil plus platinum regimens showed significantly higher rates of hematological $(P<0.001)$ and non-hematological $(P<0.001)$ toxicities than $\mathrm{S}-1$ or capecitabine regimens (Table 6). The incidence of grade 3 or 4 
Table 2 Doses and schedules of first-line chemotherapy regimens

\begin{tabular}{|c|c|c|c|}
\hline & Regimen & Schedule & $\begin{array}{l}\text { Number } \\
\text { of } \\
\text { patients } \\
(n, \%)\end{array}$ \\
\hline \multirow[t]{2}{*}{$\begin{array}{l}\text { Single group } \\
\quad(n=70)\end{array}$} & S-1 & $\begin{array}{l}\text { S-1: } 40-60 \mathrm{mg} / \mathrm{m}^{2}, \\
\text { b.i.d., p.o. days } 1-28 \text {; } \\
\text { q6w }\end{array}$ & $45(64.3)$ \\
\hline & Capecitabine & $\begin{array}{l}\text { Capecitabine : } \\
1,250 \mathrm{mg} / \mathrm{m}^{2} \text {, b.i.d., } \\
\text { p.o. days } 1-14 ; \mathrm{q} 3 \mathrm{w}\end{array}$ & $25(35.7)$ \\
\hline \multirow[t]{4}{*}{$\begin{array}{l}\text { Combination } \\
\text { group }^{\mathrm{a}} \\
(n=108)\end{array}$} & 5-FU/CDDP & $\begin{array}{l}\text { 5-FU : } 1,000 \mathrm{mg} / \mathrm{m}^{2} \text {, i.v. } \\
\text { days } 1-4 \text {; CDDP : } \\
60 \mathrm{mg} / \mathrm{m}^{2} \text {, i.v. day } 1 \text {; } \\
\text { q3w }\end{array}$ & $2(1.9)$ \\
\hline & S-1/CDDP & $\begin{array}{l}\text { S-1: } 40-60 \mathrm{mg} / \mathrm{m}^{2}, \\
\text { b.i.d., p.o. days } 1-14 \text {; } \\
\text { CDDP : } 60 \mathrm{mg} / \mathrm{m}^{2} \text {, i.v. } \\
\text { day } 1 ; \mathrm{q} 3 \mathrm{w}\end{array}$ & $11(10.2)$ \\
\hline & $\begin{array}{l}\text { Capecitabine/ } \\
\text { CDDP }\end{array}$ & $\begin{array}{l}\text { Capecitabine : } \\
\text { 1,000 mg/m } / \mathrm{m}^{2} \text { b.i.d., } \\
\text { p.o. days } 1-14 \text {; CDDP } \\
\text { : } 60 \mathrm{mg} / \mathrm{m}^{2} \text {, i.v. day } 1 ; \\
\text { q3w }\end{array}$ & $8(7.4)$ \\
\hline & FOLFOX & $\begin{array}{l}\text { Oxaliplatin : } 85 \mathrm{mg} / \mathrm{m}^{2}, \\
\text { i.v. } 5-\mathrm{FU}: 400 \mathrm{mg} / \mathrm{m}^{2}, \\
\text { bolus, i.v. and } 600 \mathrm{mg} / \\
\mathrm{m}^{2} \text {, continuous, i.v. } \\
\text { days } 1-2 ; \mathrm{FA}: \\
200 \mathrm{mg} / \mathrm{m}^{2} \text {, i.v. days } \\
1-2 ; \mathrm{q} 2 \mathrm{w}\end{array}$ & $76(70.4)$ \\
\hline
\end{tabular}

5-FU 5-fluorouracil, $C D D P$ cisplatin, $F A$ folinic acid

a In addition to fluorouracil/platinum combination regimens, paclitaxel/cisplatin $(n=5,4.6 \%)$, docetaxel/cisplatin $(n=2,1.9 \%)$, FOLFIRI $(n=2,1.9 \%)$, fluorouracil/docetaxel $(n=2,1.9 \%)$ regimens were included

Table 3 Treatment response of the first-line chemotherapy regimens

\begin{tabular}{lll}
\hline & $\begin{array}{l}\text { Single group, } \\
n(\%)\end{array}$ & $\begin{array}{l}\text { Combination group, } \\
n(\%)\end{array}$ \\
\hline Complete response & $0(0.0)$ & $1(0.9)$ \\
Partial response & $6(8.6)$ & $25(23.1)$ \\
Stable disease & $32(45.7)$ & $52(48.1)$ \\
Progressive disease & $16(22.9)$ & $18(16.7)$ \\
Unevaluable & $16(22.9)$ & $12(11.1)$ \\
Disease control rate & $38(54.3)$ & $78(72.1)$ \\
\hline
\end{tabular}

neutropenia (36.5 \% in 5-FU/platinum arm), nausea/vomiting $(75.3 \%$ in 5-FU/platinum arm) and peripheral neuropathy frequency $(28.9 \%$ in 5 -FU/platinum arm) were statistically higher in 5-FU/platinum arm than that in the S-1 or capecitabine arm $(P<0.001, P=0.013$, and $P<0.001$, respectively).
Table 4 Factors leading to cessation of first-line chemotherapy

\begin{tabular}{lll}
\hline & $\begin{array}{l}\text { Single group, } \\
n(\%)\end{array}$ & $\begin{array}{l}\text { Combination group, } \\
n(\%)\end{array}$ \\
\hline $\begin{array}{l}\text { Disease progression } \\
\begin{array}{l}\text { Decreased performance } \\
\text { status }\end{array}\end{array}$ & $32(45.7)$ & $37(34.3)$ \\
$\begin{array}{l}\text { Observation after stable } \\
\text { disease }\end{array}$ & $6(8.6)$ & $51(47.2)$ \\
$\begin{array}{l}\text { Refused treatment } \\
\text { Lost to follow-up }\end{array}$ & $3(4.3)$ & $7(6.5)$ \\
\hline
\end{tabular}

\section{Discussion}

Globally, GC is among the most common malignancies and the most common causes of cancer-related death [16]. In comparison with other malignancies, GC has moderate responsiveness to chemotherapy. A previous analyses of chemotherapy versus best supportive care (HR 0.39, $95 \%$ CI 0.28-0.52) and combination versus single-agent therapy (mainly 5-FU) (HR 0.83, $95 \%$ CI 0.74-0.93) showed significant OS advantages in favor of both chemotherapy and, specifically, combination chemotherapy [19].

However, limited data are available regarding elderly patients with recurrent or metastatic GC. Because elderly patients are underrepresented in clinical trials [10, 20-22], there has been no clear evidence for the use of systemic palliative chemotherapy in the elderly. In elderly patients with cancer, the selection of proper chemotherapy can be difficult because of impaired organ function, declined physiologic functional status, concomitant comorbidities, and other biologic problems associated with aging [23, 24]. In this study of patients who were older than 70 years, had advanced GC, and had received systemic chemotherapy as first-line therapy, the median PFS times $(4.4$ vs. 4.1 months, respectively, $P=0.295$ ) and median OS times (6.6 vs. 7.6 months, respectively, $P=0.782$ ) did not differ significantly between those receiving a single-agent regimen and those receiving a combination regimen. This finding is consistent with the results of previous studies. In the phase III SPIRITS trial, which compared the S-1/cisplatin combination with S-1 monotherapy, a subgroup analysis of the effect of S-1/CDDP (SP) on OS showed no significance (HR $0.95,95 \% \mathrm{CI}, 0.71-1.27 ; P=0.14$ ) among patients who were older than 70 years [8]. Terazawa et al. [25] reported median OS times of 10.4 months (95\% CI 8.4-12.4) for S-1 alone and 17.8 months (95\% CI, 15.0-20.6) for SP, constituting a difference that was not statistically significant. In another study, the median OS times were 14.4 months in the SP group and 10.9 months in the $\mathrm{S}-1$ group, which again did not amount to a significant difference (HR 0.99, $95 \%$ CI $0.57-1.71$ ) [26]. 

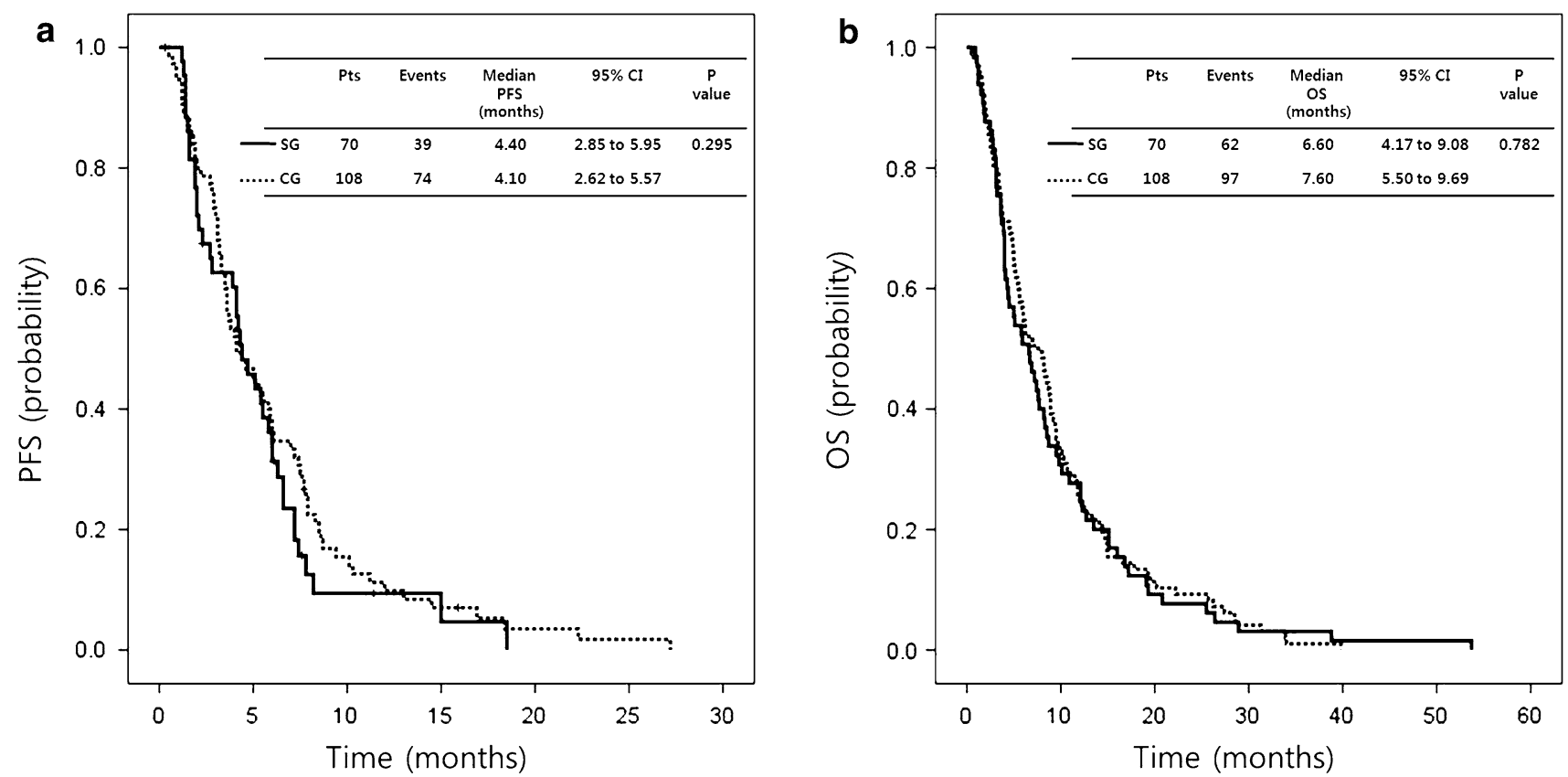

Fig. 1 a Progression-free survival (PFS) and b overall survival (OS) in each treatment arm. $P$ values were calculated using a log-rank test. Pts patients, $S G$ single regimen group, $C G$ combination regimen group

Table 5 Prognostic factors for overall survival in the Cox proportional hazards multivariate regression analysis

CI confidence interval, ECOG $P S$ Eastern Cooperative Oncology Group performance status

${ }^{\text {a }}$ Statistically significant

\begin{tabular}{|c|c|c|c|c|}
\hline \multirow[t]{2}{*}{ Characteristics } & \multicolumn{2}{|l|}{ Non-adjusted } & \multicolumn{2}{|l|}{ Recurrence-adjusted } \\
\hline & $\begin{array}{l}\text { Hazard ratio } \\
(95 \% \mathrm{CI})\end{array}$ & $P$ value & $\begin{array}{l}\text { Hazard ratio } \\
(95 \% \mathrm{CI})\end{array}$ & $P$ value \\
\hline $\begin{array}{l}\text { Treatment group (single vs. } \\
\text { combination) }\end{array}$ & $1.012(0.661-1.547)$ & 0.958 & $1.010(0.658-1.552)$ & 0.963 \\
\hline ECOG PS ( $\leq 1$ vs. $\geq 2)$ & $1.361(0.953-1.943)$ & 0.090 & $1.419(0.976-2.063)$ & 0.067 \\
\hline $\begin{array}{l}\text { Charlson comorbidity index } \\
\text { (0-2 vs. } 3-4)\end{array}$ & $0.901(0.511-1.586)$ & 0.717 & $0.803(0.443-1.458)$ & 0.472 \\
\hline T stage ( $\leq 2$ vs. $\geq 3$ ) & $1.709(0.918-3.182)$ & 0.091 & $1.724(0.910-3.268)$ & 0.095 \\
\hline $\mathrm{N}$ stage (0 vs. $\geq 1)$ & $2.990(1.191-7.510)$ & $0.020^{\mathrm{a}}$ & $3.620(1.303-10.062)$ & $0.014^{\mathrm{a}}$ \\
\hline $\begin{array}{l}\text { Number of metastasized regions } \\
(\leq 1 \text { vs. } \geq 2)\end{array}$ & $1.309(0.625-2.741)$ & 0.475 & $1.358(0.626-2.944)$ & 0.439 \\
\hline $\begin{array}{l}\text { Tumor grade (well/moderately vs. } \\
\text { poorly) }\end{array}$ & $1.198(0.820-1.750)$ & 0.351 & $1.234(0.844-1.803)$ & 0.278 \\
\hline $\begin{array}{l}\text { Hematologic toxicity grade } \\
(1-2 \text { vs. } 3-4)\end{array}$ & $1.387(0.656-2.933)$ & 0.391 & $1.434(0.680-3.024)$ & 0.344 \\
\hline Recurrence (no vs. yes) & $1.268(0.669-2.403)$ & 0.467 & & \\
\hline
\end{tabular}

Together, these results suggest that monotherapy and combination regimens may both be effective as first-line chemotherapy in elderly patients (over 70 years old) with metastatic or recurrent GC.

Chemotherapy-related toxicity has an important influence on treatment decisions. Although most measures of clinical efficacy (DCR, PFS, and OS) were similar in both groups, the CG included a greater incidence of chemotherapy-related toxicities than did the SG. Grade 3 or 4 hematologic toxicities, such as neutropenia, leukopenia, and anemia, were more common in the CG $(P<0.001)$, and there was also a greater incidence of non-hematologic toxicity in the CG. These observed toxicities would be among the leading causes of reductions to the chemotherapy dose, which was itself more common in the CG than in the SG (92.4 vs. $83.5 \%$ ). The frequency of grade $\geq 3$ toxicity observed in the present study is comparable to that found in clinical trials of platinum-based combination 
Table 6 Adverse events in the major chemotherapeutic regimens
${ }^{\text {a }}$ Fluorouracil/cisplatin, S-1/ cisplatin, capecitabine/cisplatin, FOLFOX

b Statistically significant

\begin{tabular}{|c|c|c|c|c|c|c|c|}
\hline & \multicolumn{2}{|c|}{ S-1 $(n=45)$} & \multicolumn{2}{|c|}{$\begin{array}{l}\text { Capecitabine } \\
(n=25)\end{array}$} & \multicolumn{2}{|c|}{$\begin{array}{l}\text { 5-FU/platinum }{ }^{\mathrm{a}} \\
(n=97)\end{array}$} & \multirow[t]{2}{*}{$P$ value } \\
\hline & $\begin{array}{l}\mathrm{G} 1 / 2 \\
n(\%)\end{array}$ & $\begin{array}{l}\mathrm{G} 3 / 4 \\
n(\%)\end{array}$ & $\begin{array}{l}\mathrm{G} 1 / 2 \\
n(\%)\end{array}$ & $\begin{array}{l}\mathrm{G} 3 / 4 \\
n(\%)\end{array}$ & $\begin{array}{l}\mathrm{G} 1 / 2, \\
n(\%)\end{array}$ & $\begin{array}{l}\mathrm{G} 3 / 4 \\
n(\%)\end{array}$ & \\
\hline Hematological & & & & & & & $<0.001^{\mathrm{b}}$ \\
\hline Leukopenia & $2(4.4)$ & $1(2.2)$ & $4(16.0)$ & $1(4.0)$ & $14(14.4)$ & $14(14.4)$ & 0.053 \\
\hline Neutropenia & $0(0.0)$ & $0(0.0)$ & $1(4.0)$ & $0(0.0)$ & $16(16.5)$ & $20(20.0)$ & $<0.001^{\mathrm{b}}$ \\
\hline Anemia & $14(31.1)$ & $0(0.0)$ & $7(28.0)$ & $1(4.0)$ & $32(33.0)$ & $5(5.2)$ & 0.060 \\
\hline Thrombocytopenia & $0(0.0)$ & $0(0.0)$ & $3(12.0)$ & $0(0.0)$ & $9(9.3)$ & $2(2.1)$ & 0.502 \\
\hline Non-hematological & & & & & & & $<0.001^{\mathrm{b}}$ \\
\hline Nausea/vomiting & $11(24.4)$ & $0(0.0)$ & $12(48.0)$ & $0(0.0)$ & $68(70.1)$ & $5(5.2)$ & $0.013^{\mathrm{b}}$ \\
\hline Infection & $4(8.9)$ & $1(2.2)$ & $0(0.0)$ & $0(0.0)$ & $8(8.2)$ & $1(1.0)$ & 0.071 \\
\hline Asthenia & $23(51.1)$ & $1(2.2)$ & 7 (28.0) & $0(0.0)$ & $46(47.4)$ & $8(8.2)$ & $<0.001^{\mathrm{b}}$ \\
\hline Fatigue & $13(28.9)$ & $1(2.2)$ & $4(16.0)$ & $1(4.0)$ & $38(39.1)$ & $1(2.1)$ & 0.549 \\
\hline Mucositis & $10(22.2)$ & $0(0.0)$ & $5(20.0)$ & $0(0.0)$ & $30(31.0)$ & $2(2.0)$ & 0.166 \\
\hline Diarrhea & $4(8.9)$ & $1(2.2)$ & $3(12.0)$ & $0(0.0)$ & $16(16.5)$ & $0(0.0)$ & 0.708 \\
\hline $\begin{array}{l}\text { Peripheral } \\
\text { neuropathy }\end{array}$ & $0(0.0)$ & $0(0.0)$ & $2(8.0)$ & $0(0.0)$ & $15(15.5)$ & $13(13.4)$ & $<0.001^{\mathrm{b}}$ \\
\hline Alopecia & $0(0.0)$ & $0(0.0)$ & $0(0.0)$ & $0(0.0)$ & $12(12.4)$ & $0(0.0)$ & $<0.001^{\mathrm{b}}$ \\
\hline Hand foot syndrome & $5(11.1)$ & $0(0.0)$ & $2(8.0)$ & $3(12.0)$ & $4(4.1)$ & $0(0.0)$ & $0.004^{\mathrm{b}}$ \\
\hline
\end{tabular}

regimens in the first-line treatment of advanced $\mathrm{GC}[1,7,8$, 27]. Over $95 \%$ of patients in the $\mathrm{CG}$ received platinumbased combination chemotherapy. Accordingly, the incidence of grade 3 and 4 toxicities in the $C G$ was as expected. In a previous study of a Korean cohort, both capecitabine and S-1 were found to be safe, well tolerated, and efficacious in older patients with advanced GC [18]. Together, the results of the present study and previous investigations suggest that single-agent treatment is a favorable and safe first-line chemotherapy option for elderly patients.

The evidence regarding prognostic factors for elderly patients with advanced GC has been quite limited. Kim et al. [14] reported that first-line chemotherapy was suitable for controlled disease or disease with a well-differentiated histological grade. Hwang et al. [28] reported that prognostic factors for elderly patients with advanced GC were the ECOG PS, Glasgow prognostic score, and bone metastasis. On the other hand, in a phase II trial of capecitabine versus $\mathrm{S}-1$ in elderly patients with recurrent or metastatic unresectable GC, Lee et al. [18] found that none of the potential prognostic factors were significantly predictive of OS. In the present study, OS was significantly shorter among patients who had a high $\mathrm{N}$ stage in both univariate and multivariate analyses. However, ECOG PS, CCI, and the type of chemotherapy were not significant independent prognostic factors for survival in this elderly cohort. Contrary to our expectations, PS was not significantly associated with survival in the present study. To overcome the limitations that are posed by PS in the treatment of elderly patients, the comprehensive geriatric assessment (CGA) would be a useful tool for selecting those elderly patients who would be most suitable for systemic chemotherapy with one or more agents [29].

Several limitations to the present study are worth mentioning. This study was a retrospective analysis of a small group of medical institutions, and included a highly selective cohort, which did not include comparator patients who were not treated with chemotherapy. In this study, the choice of chemotherapy (single or combination regimen) was entirely based on the physicians' decisions regarding treatment.

A meta-analysis that compared systemic single therapy with combination treatment found that combination treatment was associated with a significantly greater response rate [19]. However, the results of the present study indicate that patients who are older than 70 years and have recurrent or metastatic GC might benefit from fluoropyrimidinebased single agent palliative chemotherapy, which could manage advanced GC with favorable disease control and safety. We suggest that, as compared with combination chemotherapy, single-agent chemotherapy would be associated with a lower incidence of hematologic and nonhematologic toxicities and a similar expected duration of survival among patients who are older than 70 years and have advanced GC. Prospective randomized studies should be performed to clarify differences in outcomes and 
investigate other clinically meaningful data relevant to the treatment of advanced GC in the elderly population.

Conflict of interest All authors have no conflict of interests to declare.

\section{References}

1. Van Cutsem E, Haller D, Ohtsu A. The role of chemotherapy in the current treatment of gastric cancer. Gastric Cancer. 2002;5(Suppl 1):17-22.

2. Pyrhönen S, Kuitunen T, Nyandoto P, Kouri M. Randomised comparison of fluorouracil, epidoxorubicin and methotrexate (FEMTX) plus supportive care with supportive care alone in patients with non-resectable gastric cancer. $\mathrm{Br} \mathrm{J}$ Cancer. 1995;71(3):587-91.

3. Casaretto L, Sousa PL, Mari JJ. Chemotherapy versus support cancer treatment in advanced gastric cancer: a meta-analysis. Braz J Med Biol Res. 2006;39(4):431-40.

4. Kim NK, Park YS, Heo DS, Suh C, Kim SY, Park KC, et al. A phase III randomized study of 5-fluorouracil and cisplatin versus 5-fluorouracil, doxorubicin, and mitomycin $\mathrm{C}$ versus 5-fluorouracil alone in the treatment of advanced gastric cancer. Cancer. 1993;71(12):3813-8.

5. Ohtsu A, Shimada Y, Shirao K, Boku N, Hyodo I, Saito H, et al. Randomized phase III trial of fluorouracil alone versus fluorouracil plus cisplatin versus uracil and tegafur plus mitomycin in patients with unresectable, advanced gastric cancer: the Japan Clinical Oncology Group Study (JCOG9205). J Clin Oncol. 2003;21(1):54-9.

6. Vanhoefer U, Rougier P, Wilke H, Ducreux MP, Lacave AJ, Van Cutsem E, et al. Final results of a randomized phase III trial of sequential high-dose methotrexate, fluorouracil, and doxorubicin versus etoposide, leucovorin, and fluorouracil versus infusional fluorouracil and cisplatin in advanced gastric cancer: a trial of the European Organization for Research and Treatment of Cancer Gastrointestinal Tract Cancer Cooperative Group. J Clin Oncol. 2000;18(14):2648-57.

7. Kang YK, Kang WK, Shin DB, Chen J, Xiong J, Wang J, et al. Capecitabine/cisplatin versus 5-fluorouracil/cisplatin as first-line therapy in patients with advanced gastric cancer: a randomised phase III noninferiority trial. Ann Oncol. 2009;20(4):666-73. doi:10.1093/annonc/mdn717.

8. Koizumi W, Narahara H, Hara T, Takagane A, Akiya T, Takagi $\mathrm{M}$, et al. S-1 plus cisplatin versus S-1 alone for first-line treatment of advanced gastric cancer (SPIRITS trial): a phase III trial. Lancet Oncol. 2008;9(3):215-21. doi:10.1016/S14702045(08)70035-4.

9. Cunningham D, Starling N, Rao S, Iveson T, Nicolson M, Coxon F, et al. Capecitabine and oxaliplatin for advanced esophagogastric cancer. N Engl J Med. 2008;358(1):36-46. doi:10.1056/ NEJMoa073149.

10. Hutchins LF, Unger JM, Crowley JJ, Coltman CA Jr, Albain KS. Underrepresentation of patients 65 years of age or older in cancer-treatment trials. N Engl J Med. 1999;341(27):2061-7. doi:10. 1056/NEJM199912303412706.

11. Seo HG, Park, JH, Kim SY, Yang HK, Nam EJ. Cancer facts and figures. 1st ed ed. Republic of Korea: National Cancer Center, Minister for Health and Welfare; 2013. p. p.11.

12. Kitamura K, Yamaguchi T, Taniguchi H, Hagiwara A, Yamane $\mathrm{T}$, Sawai K, et al. Clinicopathological characteristics of gastric cancer in the elderly. Br J Cancer. 1996;73(6):798-802.
13. Kubota H, Kotoh T, Dhar DK, Masunaga R, Tachibana M, Tabara $\mathrm{H}$, et al. Gastric resection in the aged ( $>$ or $=80$ years) with gastric carcinoma: a multivariate analysis of prognostic factors. Aust NZ J Surg. 2000;70(4):254-7.

14. Kim ST, Park KH, Oh SC, Seo JH, Shin SW, Kim JS, et al. Is chemotherapy in elderly patients with metastatic or recurrent gastric cancer as tolerable and effective as in younger patients? Asia Pac J Clin Oncol. 2012;8(2):194-200. doi:10.1111/j.17437563.2011.01501.x.

15. Gridelli C, Perrone F, Gallo C, Cigolari S, Rossi A, Piantedosi F, et al. Chemotherapy for elderly patients with advanced nonsmall-cell lung cancer: the Multicenter Italian Lung Cancer in the Elderly Study (MILES) phase III randomized trial. J Natl Cancer Inst. 2003;95(5):362-72.

16. Trumper M, Ross PJ, Cunningham D, Norman AR, Hawkins R, Seymour M, et al. Efficacy and tolerability of chemotherapy in elderly patients with advanced oesophago-gastric cancer: a pooled analysis of three clinical trials. Eur $\mathrm{J}$ Cancer. 2006;42(7):827-34. doi:10.1016/j.ejca.2005.08.044.

17. Albain KS, Crowley JJ, LeBlanc M, Livingston RB. Survival determinants in extensive-stage non-small-cell lung cancer: the Southwest Oncology Group experience. J Clin Oncol. 1991;9(9):1618-26.

18. Lee JL, Kang YK, Kang HJ, Lee KH, Zang DY, Ryoo BY, et al. A randomised multicentre phase II trial of capecitabine vs S-1 as first-line treatment in elderly patients with metastatic or recurrent unresectable gastric cancer. Br J Cancer. 2008;99(4):584-90. doi:10.1038/sj.bjc.6604536.

19. Wagner AD, Grothe W, Haerting J, Kleber G, Grothey A, Fleig WE. Chemotherapy in advanced gastric cancer: a systematic review and meta-analysis based on aggregate data. J Clin Oncol: Off J Am Soc Clin Oncol. 2006;24(18):2903-9. doi:10.1200/ JCO.2005.05.0245.

20. Lichtman SM, Balducci L, Aapro M. Geriatric oncology: a field coming of age. J Clin Oncol. 2007;25(14):1821-3. doi:10.1200/ JCO.2007.10.6567.

21. Lewis JH, Kilgore ML, Goldman DP, Trimble EL, Kaplan R, Montello MJ, et al. Participation of patients 65 years of age or older in cancer clinical trials. $J$ Clin Oncol. 2003;21(7):1383-9.

22. Murthy VH, Krumholz HM, Gross CP. Participation in cancer clinical trials: race-, sex-, and age-based disparities. JAMA. 2004;291(22):2720-6. doi:10.1001/jama.291.22.2720.

23. Repetto L, Balducci L. A case for geriatric oncology. Lancet Oncol. 2002;3(5):289-97.

24. Lichtman SM, Wildiers H, Chatelut E, Steer C, Budman D, Morrison VA, et al. International Society of Geriatric Oncology Chemotherapy Taskforce: evaluation of chemotherapy in older patients-an analysis of the medical literature. J Clin Oncol. 2007;25(14):1832-43. doi:10.1200/JCO.2007.10.6583.

25. Terazawa T, Iwasa S, Takashima A, Nishitani H, Honma Y, Kato $\mathrm{K}$, et al. Impact of adding cisplatin to S-1 in elderly patients with advanced gastric cancer. J Cancer Res Clin Oncol. 2013;139(12):2111-6. doi:10.1007/s00432-013-1537-7.

26. Tsushima T, Hironaka S, Boku N, Machida N, Yamazaki K, Yasui $\mathrm{H}$, et al. Comparison of safety and efficacy of S-1 monotherapy and S-1 plus cisplatin therapy in elderly patients with advanced gastric cancer. Int J Clin Oncol. 2013;18(1):10-6. doi:10.1007/s10147-011-0335-y.

27. Ajani JA, Rodriguez W, Bodoky G, Moiseyenko V, Lichinitser $\mathrm{M}$, Gorbunova V, et al. Multicenter phase III comparison of cisplatin/S-1 with cisplatin/infusional fluorouracil in advanced gastric or gastroesophageal adenocarcinoma study: the FLAGS trial. J Clin Oncol. 2010;28(9):1547-53. doi:10.1200/JCO.2009. 25.4706 . 
28. Hwang JE, Kim HN, Kim DE, Choi HJ, Jung SH, Shim HJ, et al. Prognostic significance of a systemic inflammatory response in patients receiving first-line palliative chemotherapy for recurred or metastatic gastric cancer. BMC Cancer. 2011;11:489. doi:10. 1186/1471-2407-11-489.

29. Repetto L, Fratino L, Audisio RA, Venturino A, Gianni W, Vercelli $\mathrm{M}$, et al. Comprehensive geriatric assessment adds information to Eastern Cooperative Oncology Group performance status in elderly cancer patients: an Italian Group for Geriatric Oncology Study. J Clin Oncol. 2002;20(2):494-502. 